We set out to produce a blueprint for the kind of mental health service MIND would like to see implemented. From the outset we dismissed the idea of producing another model that would simply be the status quo by another name. We went for an approach that we hoped would be regarded as innovatory and visionary. As such it will doubtlessly be

\section{References}

DHSS (1975) Better Services for the Mentally Ill. London: HMSO.

FeinmanN, J. (1985) An experiment paying dividends. Health and Social Services Journal, 3 October.

GOLDBERG, D. \& HuXLEY, P. (1980) Mental Illness in the Community: Pathways to Psychiatric Care. London: Tavistock.

Griffiths, SRR RoY (1988) Community Care: Agenda for Action. London: HMSO. seen in some circles as unworkable idealism. However, we think that it will work. We are convinced that it is an intelligent synthesis of what we know and a logical extension of what Griffiths has meant to us. And we are confident that there are enough people interested in mental health to give our ideas serious consideration.

MIND (1984) Common Concern: MIND's Manifesto for a New Mental Health Service. London: MIND.

Northern Regional Health Authority (1987) Planning Guidelines 1988/9-1989/90.

Ruchardson, K. (1988) Let's Not Mince Words: The State of Mental Health Care in the Northern Region. Northern MIND.

\title{
Co-ordinating care for people disabled by long-term mental illness living in the community
}

\author{
Margaret Rich, Community Psychiatrist; MARY Ness, Joint Coordinator; and \\ TOM SMYTH, Support Worker; Community Psychiatry Research Unit, Hackney Hospital, \\ London E9
}

The Community Psychiatry Research Unit at Hackney Hospital have established a support team for the care of people disabled by long-term mental illness living in the community. The work of the support team in coordinating and managing the care of their clients in supportive accommodation using a review system and an information package is described.

The recent Griffiths Report (1988) contained the recommendation that people with long-termillness or disability should not be discharged into the community without a named keyworker and a package of care. This has long been a guiding principle for the support service provided through the Community Psychiatry Research Unit (CPRU) at Hackney Hospital for people disabled by long-term mental illness.

In 1979 CPRU was set up to investigate the needs of mentally ill people within the district, to explore ways in which these needs could be met, and to develop a comprehensive range of services in the community. CPRU was expected to take whatever role was necessary, such as catalyst, instigator, helper, or coordinator, to develop projects which demonstrated how these improvements could be translated into action (Lovett, 1979).

\section{The support team}

As part of this original brief CPRU set up several accommodation projects. The early projects revealed the need for support workers who could assess people's suitability for the different types of accommodation, and provide a support package based on an individual's needs. With the cooperation of the local housing department, the CPRU Support Team has developed two main supportive accommodation schemes, the Independent Living Scheme and the Family Support project.

The support team now have 40 people living alone in accommodation negotiated by the team with the Housing Department, eight people in shared flats, two in adult fostering, two in sheltered housing, four live independently in their own accommodation, five families living in family accommodation set up by the team with the local Housing Department, and two families in housing association accommodation. Two clients have ceased to live on their own and now live with their families and receive intermittent support. A further 20 clients live in other accommodation, are being assessed, or awaiting accommodation. 
People are referred for housing in these schemes by a wide range of agencies and are assessed by the support workers either in their present accommodation or on the ward. The support worker's assessment consists of an unstructured interview where the client is encouraged to talk about him or herself and where he or she would like to live. The criteria for acceptance are that the client can accept the support of the support worker, has minimal life skills, and some understanding of what living independently or sharing a flat in the community entails.

The support package offered by the support worker can include practical help for the client (such as help in obtaining welfare benefits), liaising with other services (such as day centres, GPs, housing departments) as well as emotional support and counselling. The team is a multidisciplinary one with extensive knowledge and a varied range of skills and this is reflected in the comprehensive support with which each client is provided.

As well as the input from the support worker, the client is offered visits from a concerned neighbour and a handyperson to help decorate his/her flat. The concerned neighbours provide a crucial front line service for the supportive accommodation schemes and are recruited from the local tenants' associations.

Originally it was envisaged that the support worker would be involved on a short-term intensive basis, and then the mainline statutory services would take on the long-term responsibility for their clients. This plan was abandoned for two reasons. The first was that Social Services could only respond to crises and were too hard-pressed to carry out maintenance and preventive care. The second was that strong bonds were forged between the support team and the individual clients as they were helped to set up their home in the community (probably the first home of their own), and it seemed wasteful not to use this good client-worker relationship for ongoing support.

Faced with the long-term needs of their clients, the support team developed a case-management role for themselves and, to provide a structure for this ongoing care, they evolved a review system.

\section{The review system}

Reviews are held on all clients at varying intervals: the time interval is related to client need and if a crisis develops a review can be quickly convened. The reviews are attended by the client (if possible), the support worker, the consultant or community psychiatrist, and any other agency worker involved.

The review begins by referring to the Action Plan of the last review and records the actions carried out. A brief summary of events since the last review is provided by the support worker, which includes the reason for the review, the client's medication, if they are attending out-patients or the depot clinic regularly (if necessary), and the number of hospital admissions (if any). The client's current physical and mental condition is considered. This is easier to assess if the client attends; if not, it is done from the support worker's report or hospital notes. The client's daytime activities, social contacts, and housekeeping are included in the review as is any involvement by the concerned neighbours.

Clients who attend their reviews can discuss their progress and future with their support worker and their psychiatrist. The client is encouraged to bring a friend or relative but, in the absence of a trusted person, or even of the client themselves, the keyworker will put the client's position based on regular and recent visits. A care plan incorporating the short and long term needs of the clients is worked out, as is an action plan which includes the support worker.

\section{The information package}

Since April 1988 information packages have also been made available for clients (Turner et al, 1988). These are produced on a micro-computer using the 'Homepack' case management software package, and set out the care plan for the client, their medication (if any) with dosage and warnings of any possible side effects, and the date of their next review. Other information includes the names of all professionals involved in their care, and how these people can be contacted. Where appropriate, and with the informed agreement of the client, further, tailored copies of the pack are available for a person they trust, their GP and all other agencies involved.

All copies are produced automatically from the same basic information recorded at the review. As well as giving the client a greater awareness of their own situation, the system aims to improve the coordination of care, offer some support to sometimes hard-pressed relatives and friends, and to cater for all administrative requirements of the support team.

Not all clients can use the Homepacks and for some, who are being seen frequently by their support workers, the Homepack is not appropriate. However, as the support team are now broadening their work to include clients living in their own accomodation, Homepacks are seen as providing essential information and coordination.

\section{References}

GrIFfTHS, SIR RoY (1988). Community Care: Agenda for Action. London: HMSO.

LOVETT, A. (1979) GPMH Project Sheet, Community Psychiatry Research Unit, Hackney, London E9.

Turner, T., Martindale, D. N., Ness, M. \& Wright, J. (1988) Coordinating care. Homepack: The use of a computer in community care. Bulletin of the Royal College of Psychiatrists, 12, 370-372. 